\title{
Tyrosine Phosphatases Regulate AMPA Receptor Trafficking during Metabotropic Glutamate Receptor-Mediated Long-Term Depression
}

\author{
Peter R. Moult, Clare M. Gladding, Thomas M. Sanderson, Stephen M. Fitzjohn, Zafar I. Bashir, Elek Molnar, and \\ Graham L. Collingridge \\ Medical Research Council Centre for Synaptic Plasticity, Department of Anatomy, University of Bristol, School of Medical Sciences, Bristol BS8 1TD, United \\ Kingdom
}

Two forms of long-term depression (LTD), triggered by activation of NMDA receptors (NMDARs) and metabotropic glutamate receptors (mGluRs), respectively, can be induced at CA1 synapses in the hippocampus. Compared with NMDAR-LTD, relatively little is known about mGluR-LTD. Here, we show that protein tyrosine phosphatase (PTP) inhibitors, orthovanadate and phenylarsine oxide, selectively block mGluR-LTD induced by application of the group I mGluR agonist $(R S)$-3,5-dihydroxyphenylglycine (DHPG-LTD), because NMDAR-LTD is unaffected by these inhibitors. Furthermore, DHPG-LTD measured using whole-cell recording is similarly blocked by either bath-applied or patch-loaded PTP inhibitors. These inhibitors also block the changes in paired-pulse facilitation and coefficient of variation that are associated with the expression of DHPG-LTD. DHPG treatment of hippocampal slices was associated with a decrease in the level of tyrosine phosphorylation of GluR2 AMPA receptor (AMPAR) subunits, an effect blocked by orthovanadate. Finally, in dissociated hippocampal neurons, orthovanadate blocked the ability of DHPG to reduce the number of AMPA receptor clusters on the surface of dendrites. Again, the effects of PTP blockade were selective, because NMDA-induced decreases in surface AMPAR clusters was unaffected by orthovanadate. Together, these data suggest that activation of postsynaptic PTP results in tyrosine dephosphorylation of AMPARs and their removal from the synapse.

Key words: long-term depression; metabotropic glutamate receptor; AMPA receptor; tyrosine phosphorylation; protein tyrosine phosphatase; hippocampus

\section{Introduction}

The ability to regulate synaptic strength is a critical feature of the CNS and is thought to underlie processes such as learning and memory. Long-term potentiation and long-term depression (LTD) have been studied intensely to understand the cellular and molecular mechanisms of synaptic plasticity (Bliss and Collingridge, 1993; Bear and Abraham, 1996). In the CA1 region, two forms of LTD can be distinguished based on their induction mechanisms; one requires activation of NMDA receptors (NMDARs) (Dudek and Bear, 1992; Mulkey and Malenka, 1992; Oliet et al., 1997), and the other the activation of metabotropic glutamate receptors (mGluRs; mGluR-LTD) (Bashir et al., 1993; Bashir and Collingridge, 1994; Bolshakov and Siegelbaum, 1994; Oliet et al., 1997). These two forms of LTD can be induced by agonists selective for NMDARs (Lee et al., 1998) and group I mGluRs (Palmer et al., 1997), respectively. Indeed, the group I mGluR agonist $(R S)$-3,5-dihydroxyphenylglycine (DHPG) is used widely to

\footnotetext{
Received June 20,2005; revised Jan. 6, 2006; accepted Jan. 6, 2006.

We are grateful to the Medical Research Council and the Wellcome Trust for financial support.

Correspondence should be addressed to Dr. Peter Moult, Medical Research Council Centre for Synaptic Plasticity, Department of Anatomy, University of Bristol, School of Medical Sciences, University Walk, Bristol BS8 1TD, UK. E-mail:p.r.moult@bristol.ac.uk.

DOI:10.1523/JNEUROSCI.4322-05.2006

Copyright $\odot 2006$ Society for Neuroscience $\quad$ 0270-6474/06/262544-11\$15.00/0
}

study mGluR-LTD (Palmer et al., 1997; Fitzjohn et al., 1999; Huber et al., 2000; Rouach and Nicoll, 2003; Tan et al., 2003; Gallagher et al., 2004; Huang et al., 2004). This DHPG-induced LTD (DHPG-LTD) has the important advantage of maximizing the number of synapses affected, facilitating investigations into the underlying biochemical mechanisms.

NMDAR-LTD involves an increase in postsynaptic $\mathrm{Ca}^{2+}$, activation of serine/threonine phosphatases, dephosphorylation of the GluR1 subunit at ser845 (Lee et al., 1998), and internalization of AMPA receptors (AMPARs) (Luthi et al., 1999; Beattie et al., 2000) at extrasynaptic sites (Ashby et al., 2004). DHPG-LTD does not occlude with NMDAR-LTD (Palmer et al., 1997; Fitzjohn et al., 1999; Huber et al., 2001) and is independent of $\mathrm{Ca}^{2+}$ (Fitzjohn et al., 2001) and serine/threonine phosphatases (Schnabel et al., 2001), indicating a very different underlying mechanism. DHPG-LTD involves activation of G-proteins (Watabe et al., 2002; Huang et al., 2004), protein tyrosine phosphatases (PTPs) (Moult et al., 2002), mitogen-activated protein kinase (MAPK) cascades (Gallagher et al., 2004; Huang et al., 2004), and postsynaptic protein synthesis (Huber et al., 2000). However, the mechanism of expression of DHPG-LTD is unclear. For example, DHPG-LTD involves alterations in paired-pulse facilitation (PPF) (Fitzjohn et al., 2001; Watabe et al., 2002; Rouach and Nicoll, 2003; Tan et al., 2003) but no change in sensitivity to 
uncaged L-glutamate (Rammes et al., 2003), which is suggestive of a presynaptic alteration. In contrast, DHPG-LTD is prevented by inhibitors of endocytosis or protein synthesis applied to the postsynaptic cell and involves changes in the surface distribution of GluR1 subunits in both slices and cultured hippocampal neurons (Snyder et al., 2001; Xiao et al., 2001; Huang et al., 2004). It has been suggested that differences in the mechanisms of DHPGLTD expression could be explained by a developmental switch from presynaptic to postsynaptic changes occurring at $\sim 2$ weeks of age (Nosyreva and Huber, 2005).

In the present study, we investigated the role of PTPs in the expression mechanisms of DHPG-LTD. We show that PTP inhibitors block DHPG-LTD and the associated changes in pairedpulse facilitation, tyrosine dephosphorylation, and trafficking of AMPARs.

\section{Materials and Methods}

Hippocampal slice preparation. Hippocampal slices (400 $\mu \mathrm{m}$ thick) were obtained from female Wistar rats (10-12 weeks of age, unless otherwise stated). Animals were killed by cervical dislocation in accordance with UK Animal (Scientific Procedures) legislation. The brains were removed rapidly and placed in ice-cold artificial CSF (aCSF) consisting of the following (in mM): $124 \mathrm{NaCl}, 3 \mathrm{KCl}, 26 \mathrm{NaHCO}_{3}, 1.25 \mathrm{NaH}_{2} \mathrm{PO}_{4}, 2$ $\mathrm{CaCl}_{2}, 1 \mathrm{MgSO}_{4}$, and 10 D-glucose (bubbled with $95 \% \mathrm{O}_{2} / 5 \% \mathrm{CO}_{2}$ ). Parasaggital brain slices were then prepared and the hippocampus isolated from surrounding tissue. The CA3 region was removed in all cases. Slices were allowed to recover at room temperature in oxygenated aCSF for at least $1 \mathrm{~h}$ before use.

Cell culture. Primary rat hippocampal neuronal cultures were prepared as described previously (Pickard et al., 2000, 2001) with a few modifications. The CA3-CA1 region of the hippocampus from 1- to 3 -d-old rat pups was dissected at $4^{\circ} \mathrm{C}$, and the neurons were recovered by enzymatic digestion with trypsin and mechanical dissociation. Cells were then plated at a density of $\sim 50,000$ per dish onto $22 \mathrm{~mm}$ glass coverslips coated with poly-D-lysine $(0.5 \mathrm{mg} / \mathrm{ml}$; Sigma, Poole, Dorset, UK). Cultures were maintained at $37^{\circ} \mathrm{C}$ in a $95 \% \mathrm{O}_{2}, 5 \% \mathrm{CO}_{2}$ humidified incubator. The culture media were composed of Neurobasal A (Invitrogen, Paisley, UK) supplemented with $2 \mathrm{~mm}$ glutamine, $2 \%$ B27, 10\% horse serum, and $2 \mathrm{mg} / \mathrm{ml}$ gentamycin. From the second day, the B27 and horse serum content of the medium was reduced to $1 \%$. From the third day in culture, the media were supplemented with $10 \mu \mathrm{M}$ uradine and $10 \mu \mathrm{M}$ 5 -fluoro-2'-deoxyuridine (Sigma) to prevent glial cell proliferation. Culture media were changed twice a week. Neurons were used for experiments 13-15 d after plating.

Extracellular recordings. Grease-gap recordings were obtained from the CA1 region as described previously (Blake et al., 1988; Moult et al., 2002). Briefly, slices were placed on a glass coverslip on the surface of an inclined temperature-controlled unit (maintained at $\sim 30^{\circ} \mathrm{C}$ ). The slice was partially covered with absorbent paper and superfused at a rate of 2 $\mathrm{ml} / \mathrm{min}$ with aCSF (composition as above) bubbled continuously with $95 \% \mathrm{O}_{2} / 5 \% \mathrm{CO}_{2}$. For DHPG-LTD experiments, the $\mathrm{GABA}_{\mathrm{A}}$ receptor antagonist picrotoxin $(50 \mu \mathrm{M})$ and the NMDAR antagonist L- 689,560 (trans-2-carboxy-5,7-dichloro-4-phenylaminocarbonylamino-1,2,3,4tetrahydroquinoline; $5 \mu \mathrm{M}$ ) were present throughout (Moult et al., 2002). The Schaffer collateral-commissural pathway was stimulated at $0.033 \mathrm{~Hz}$ at an intensity that evoked a field EPSP (fEPSP) slope of $\sim 50 \%$ of the maximum. Responses were digitized at $5 \mathrm{kHz}$ and recorded on-line using the LTP program (Anderson and Collingridge, 2001). The maximum slope was obtained from $20-80 \%$ of the incline of the response.

Whole-cell recordings from hippocampal slices. Slices were transferred to a submerged recording chamber maintained at $30^{\circ} \mathrm{C}$ and perfused continuously with aCSF (composition as above) at a rate of $2-3 \mathrm{ml} / \mathrm{min}$. The $\mathrm{GABA}_{\mathrm{A}}$ receptor antagonist picrotoxin $(50 \mu \mathrm{M})$ and the NMDA receptor antagonist L-689,560 (5 $\mu \mathrm{M})$ were present throughout. Electrodes with a resistance in the range of 4-7 M $\Omega$ were filled with Cs-based filling solution, which comprised the following (in mM): $130 \mathrm{CsMeSO}_{4}, 8 \mathrm{NaCl}, 4$ Mg-ATP, 0.3 Na-GTP, 0.5 EGTA, 10 HEPES, and N-(2,6-dimethyl- phenylcarbamoylmethyl)triethylammonium chloride. The $\mathrm{pH}$ was adjusted to 7.2-7.3 using $\mathrm{CsOH}$, while osmolarity was adjusted to 275-290 mOsm with sucrose if necessary. Where PTP inhibitors were included in the filling solution, these were used at 10-fold lower concentration than used extracellularly, and adjustments to $\mathrm{pH}$ and osmolarity were made accordingly. Blind whole-cell recordings were made from neurons in the CA1 pyramidal layer voltage clamped at $-70 \mathrm{mV}$. The Schaffer collateral-commissural pathway was stimulated at $0.033 \mathrm{~Hz}$. The stimulus intensity used was that which evoked a peak amplitude of $\sim 50 \%$ of the maximum. Responses were digitized at $10 \mathrm{kHz}$.

Whole-cell recordings from hippocampal cultures. Whole-cell recordings from pyramidal neurons were obtained as previously detailed (Fitzjohn et al., 2001). Cells were voltage clamped at $-70 \mathrm{mV}$ using the same intracellular solutions used for recording from hippocampal slices. Cells were perfused continuously with HEPES-buffered saline (HBS) of the following composition (in mM): $119 \mathrm{NaCl}, 5 \mathrm{KCl}, 2 \mathrm{CaCl}_{2}, 2 \mathrm{MgCl}_{2}, 25$ HEPES, 33 D-glucose, 0.005 tetrodotoxin citrate, 0.1 picrotoxin, and 0.001 glycine, $\mathrm{pH} 7.4$, at a rate of $2-3 \mathrm{ml} \cdot \mathrm{min}^{-1}$. DHPG was applied by addition to the HBS perfusate. Data were filtered at $2 \mathrm{kHz}$ and digitized at $10 \mathrm{kHz}$. Continuous recording of miniature EPSCs (mEPSCs) was made using Axoscope software (Molecular Devices, Union City, CA) and series resistance measured using the LTP program.

Electrophysiological analysis. fEPSPs and EPSC data from hippocampal slices were monitored on-line and analyzed off-line using the LTP program (Anderson and Collingridge, 2001). LTD was calculated 25-30 min after washout of the agonist and expressed as a percentage of the baseline. The paired-pulse ratio (PPR) was calculated as the ratio of the amplitude of the second EPSC to the first EPSC. To ensure that the measurement of the peak amplitude of the second EPSC was not contaminated by residual current from the first EPSC, the residual component was removed. This was done by extrapolation of the first EPSC and using this point to calculate the peak using the MiniAnalysis 5.6.25 program (Synaptosoft, Decatur, GA). The PPR was calculated from an average of five successive sweeps immediately before DHPG, during, and between 25 and $30 \mathrm{~min}$ after DHPG application ceased. The coefficient of variation (CV) was calculated as described previously (Kullmann, 1994; Fitzjohn et al., 2001). Briefly, the mean and SD were calculated for the EPSC amplitudes recorded during successive 5 min epochs $\left(\mathrm{SD}_{\mathrm{EPSC}}\right.$ and mean $\left.{ }_{\mathrm{EPSC}}\right)$. The $\mathrm{SD}$ of the background noise was also calculated for each $5 \mathrm{~min}$ epoch using a period immediately before electrical stimulation $\left(\mathrm{SD}_{\text {Noise }}\right)$. The $\mathrm{CV}$ for each epoch was calculated as $\left(\mathrm{SD}_{\mathrm{EPSC}}-\mathrm{SD}_{\text {Noise }}\right) / \mathrm{mean}_{\mathrm{EPSC}}$.

mEPSC detection was performed using MiniAnalysis software (Synaptosoft). Events were detected by setting the threshold value for detection at three times the level of the root mean square noise, followed by visual confirmation of mEPSC detection. For construction of cumulative probability plots, 400 successive events were used from the period immediately preceding application of DHPG and from the period before 30 min after commencing washout of DHPG. For pooled cumulative probability plots, data were normalized to the median value in the pre-DHPG period.

Statistical analysis was performed using Student's $t$ test. $n$ signifies the number of times a given experiment was performed, with each experiment using a slice from a different rat. Experimental treatments and corresponding control experiments were interleaved throughout. Where multiple comparisons were made against one of the control groups (see Figs. 1-3), an ANOVA with post hoc Bonferroni's test was applied.

Immunoprecipitation and immunoblot analysis. Hippocampal slices were taken at the end of a $10 \mathrm{~min}$ DHPG application or after $30 \mathrm{~min}$ washout. These slices, and parallel controls, were then homogenized in Eppendorf Scientific (Westbury, NY) tubes with a pellet pestle on ice in $11 \%(\mathrm{w} / \mathrm{v})$ sucrose, $10 \mathrm{~mm}$ HEPES, $\mathrm{pH}$ 7.2, $100 \mu \mathrm{m}$ genistein, $1 \mathrm{~mm}$ orthovanadate in the presence of a mixture of "complete" protease inhibitors (Roche Products, Welwyn Garden City, UK) and phosphatase inhibitor mixture 1 (Sigma) to prevent degradation and dephosphorylation of proteins. Homogenized samples were centrifuged at $1000 \times g$ for $15 \mathrm{~min}$ at $4^{\circ} \mathrm{C}$ to remove tissue debris. Supernatants were spun at $100,000 \times g$ for $1 \mathrm{~h}$ at $4^{\circ} \mathrm{C}$ and pellets then stored at $-80^{\circ} \mathrm{C}$.

Membrane proteins were solubilized in $500 \mu \mathrm{l}$ of lysis buffer $[1 \%(\mathrm{v} / \mathrm{v})$ Triton X-100, 0.1\% (w/v) SDS, $150 \mathrm{~mm} \mathrm{NaCl}, 20 \mathrm{~mm}$ HEPES, $2 \mathrm{~mm}$ 
EDTA, $100 \mu \mathrm{m}$ genistein, and $1 \mathrm{~mm}$ orthovanadate in the presence of a mixture of complete protease inhibitors (Roche Products) and phosphatase inhibitor mixture 1 (Sigma)]. Samples were sonicated and rotated for $1-2 \mathrm{~h}$ at $4^{\circ} \mathrm{C}$, followed by centrifugation at $100,000 \times g$ for $30 \mathrm{~min}$ at $4^{\circ} \mathrm{C}$. After removing a $50 \mu \mathrm{l}$ aliquot for a whole input sample, supernatants were incubated with rabbit anti-GluR1-4 antibody (3.5 $\mu \mathrm{l}$ per slice) (Pickard et al., 2000) overnight at $4^{\circ} \mathrm{C}$. Sepharose A beads $[8 \mu \mathrm{l}$ per slice; pretreated with $5 \%(\mathrm{w} / \mathrm{v}) \mathrm{BSA}$ in lysis buffer for $30 \mathrm{~min}$; Sigma] were used to separate antibody/AMPAR complexes. After $2 \mathrm{~h}$ incubation at $4^{\circ} \mathrm{C}$, Sepharose beads were separated by centrifugation $\left(1000 \times g, 5 \mathrm{~min}, 4^{\circ} \mathrm{C}\right)$, and aliquots of the supernatants were mixed with 1:1 ratio of $2 \times$ SDS sample buffer $[2 \%(w / v)$ SDS, 50 mм Tris- $\mathrm{HCl}, \quad \mathrm{pH} \quad 6.8, \quad 10 \% \quad(\mathrm{v} / \mathrm{v})$ 2-mercaptoethanol, $10 \%(\mathrm{v} / \mathrm{v})$ glycerol, $0.1 \%$ $(\mathrm{w} / \mathrm{v})$ bromophenol blue] and stored at $-20^{\circ} \mathrm{C}$. Beads were washed with 1 and $0.1 \%(\mathrm{v} / \mathrm{v})$ Triton X-100-containing lysis buffer (two times in each) and once with PBS supplemented with $100 \mu \mathrm{m}$ genistein, $1 \mathrm{~mm}$ orthovanadate in the presence of a mixture of complete protease inhibitors (Roche Products) and phosphatase inhibitor mixture 1 (Sigma). Proteins associated with Sepharose beads were extracted with $2 \times$ SDS-PAGE sample buffer at $37^{\circ} \mathrm{C}$ for $10 \mathrm{~min}$.

For the separate immunoprecipitation of GluR1 and GluR2 proteins, AMPA receptor subunits were dissociated in a modified radioimmunoprecipitation assay (RIPA) buffer [ $1 \%$ $(\mathrm{v} / \mathrm{v})$ Triton X-100, 1\% (w/v) SDS, $0.4(\mathrm{w} / \mathrm{v})$ sodium deoxycholate, 2 mm EDTA, $150 \mathrm{~mm}$ $\mathrm{NaCl}, 50 \mathrm{~mm}$ Tris-HCl, pH 7.4] in the presence of protease and phosphatase inhibitors at $100^{\circ} \mathrm{C}$ for $5 \mathrm{~min}$. Individual subunits were immunoprecipitated using mouse anti-GluR2 (0.5 mg per slice; MAB397; Chemicon, Temecula, CA), rabbit anti-GluR2 (0.4 mg per slice; AB1768-25UG; Chemicon), or rabbit anti-GluR1 (0.4 mg per slice; catalog \#07-660; Upstate Biotechnology, Lake Placid, NY) antibodies using the above-described procedure.

Immunoprecipitated proteins were separated on $8 \%(w / v)$ SDS-PAGE gels followed by transfer electrophoretically onto polyvinylidene difluoride membranes using an Atto (Tokyo, Japan) HorizBlot electrophoretic transfer unit with a discontinuous buffer system for $1.5 \mathrm{~h}$ at room temperature, as recommended by the manufacturer. Before the immunostaining with the anti-phosphotyrosine P-Y20horseradish peroxidase (HRP)-conjugated antibody (ICN Biomedicals, Costa Mesa, CA), membranes were blocked with TBS containing $1 \%(\mathrm{w} / \mathrm{v})$ ovalbumin, $3 \%(\mathrm{w} / \mathrm{v}) \mathrm{BSA}$, and $0.1 \%$ $(\mathrm{v} / \mathrm{v})$ Tween 20 for $1 \mathrm{~h}$ at $4^{\circ} \mathrm{C}$. Blots were blocked with $5 \%(\mathrm{w} / \mathrm{v})$ milk, $0.1 \%(\mathrm{v} / \mathrm{v})$ Tween 20 in TBS for $1 \mathrm{~h}$ at $4^{\circ} \mathrm{C}$ before labeling with the guinea pig anti-GluR1-4 antibody (Pickard et al., 2001) After three washes in $0.1 \%$ Tween 20 in TBS (TBST), blots were incubated with the P-Y20-HRP antibody (1:5000 dilution) in 1\% ovalbumin, 3\% BSA in TBST, or in guinea pig anti-GluR1-4 antibody (1:2000 dilution), rabbit anti-GluR1 $(1.96 \mathrm{mg} / \mathrm{ml})$, mouse anti-
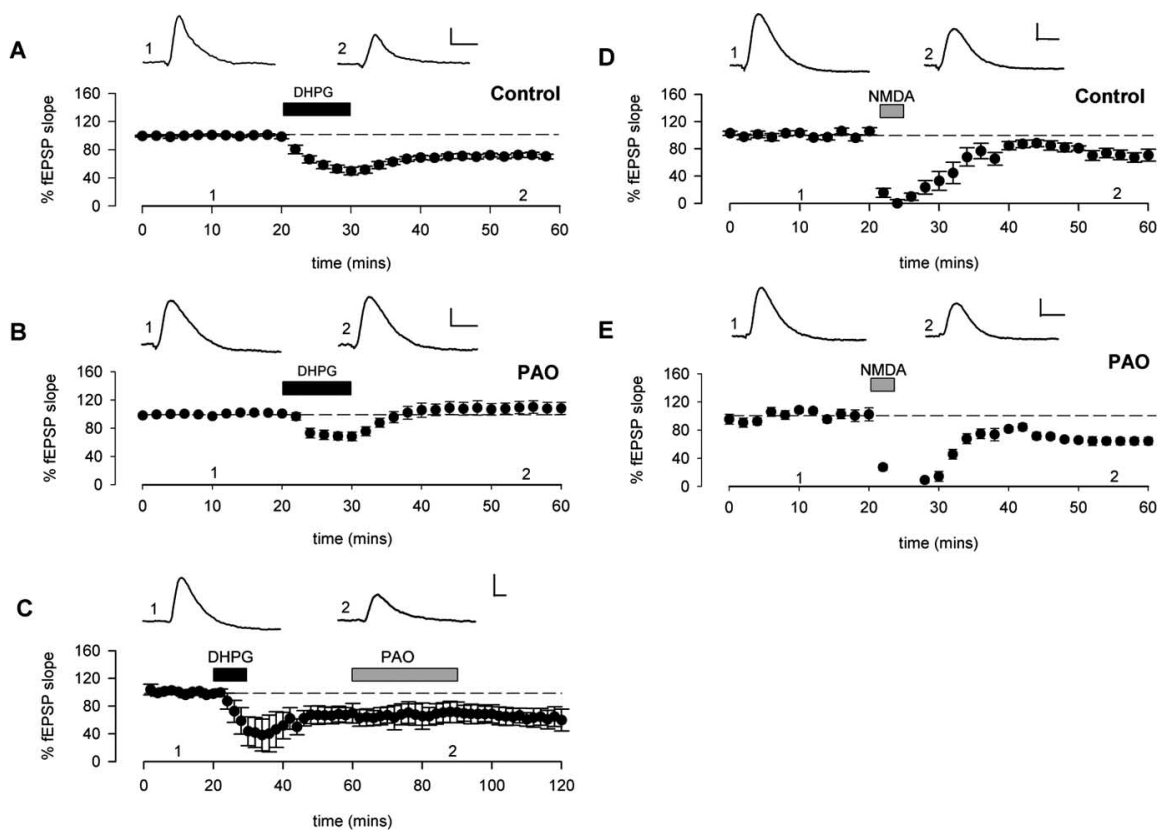

Figure 1. PTPs are selectively involved in DHPG-LTD. Pooled data from control experiments are shown as percentage fEPSP slope versus time. In this and subsequent figures, each point is the average of four successive responses, and example traces are from an individual representative experiment shown at the time points indicated. $A$, Bath application of DHPG (100 $\mu \mathrm{m}, 10 \mathrm{~min})$ induces LTD of fEPSPS. $\boldsymbol{B}$, DHPG-LTD is blocked by bath application of the PTP inhibitor PAO (15 $\mu \mathrm{m})$. In $\boldsymbol{B}$ and $\boldsymbol{E}$, PAO was present throughout the illustrated portion of the experiment. The PTP inhibitors were applied for 20-30 min before the addition of DHPG. C, Bath application of PAO has no significant effect on the expression of DHPG-LTD. D, Bath application of NMDA (20 $\mu \mathrm{M}, 3 \mathrm{~min})$ induces LTD of fEPSPs. $\boldsymbol{E}$, NMDAR-LTD is not blocked by bath application of PAO. The data illustrated in $\boldsymbol{A}$ and $\boldsymbol{B}$ are replotted from Moult et al. (2002). Calibration: $0.5 \mathrm{mV}, 5 \mathrm{~ms}$. Data are represented as mean \pm SEM.
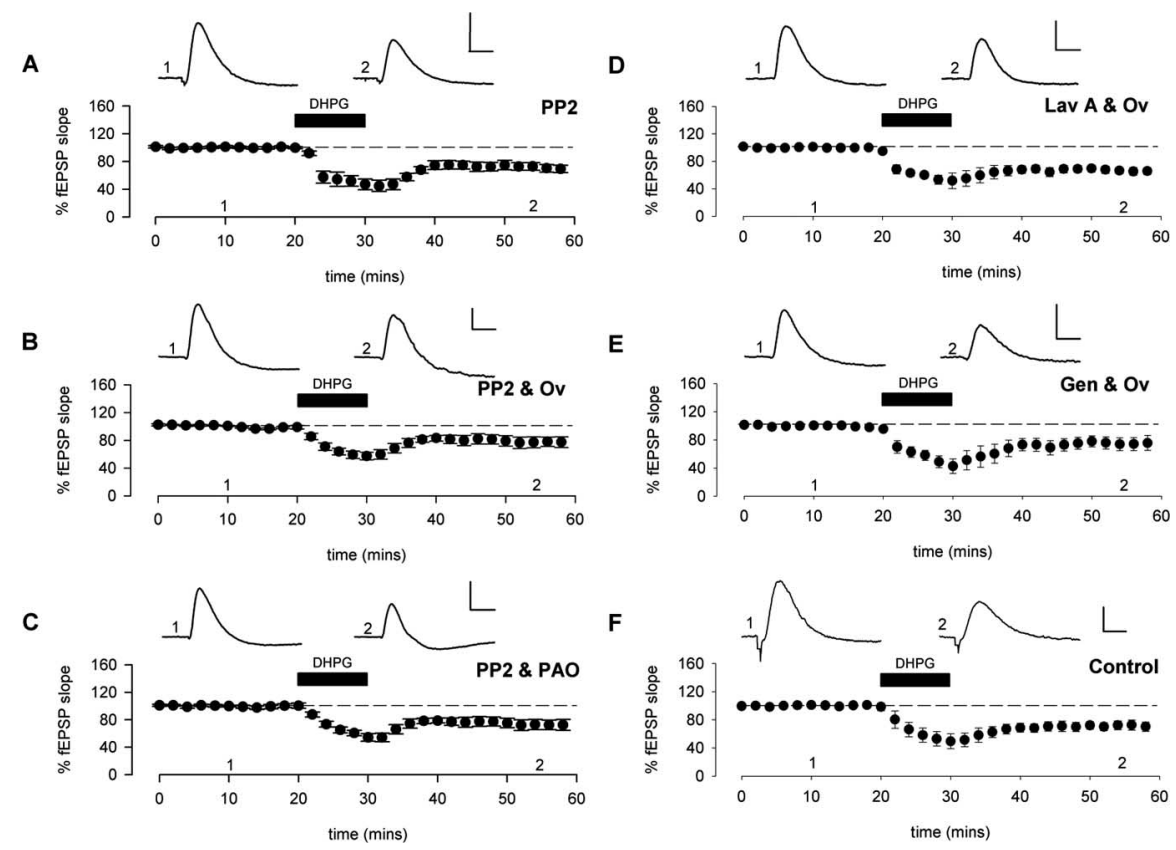

Figure 2. Block of DHPG-LTD by PTP inhibitors is prevented by inhibition of PTK. Data are presented as in Figure 1. When used, PTP and PTK inhibitors were present throughout. $A$, Bath application of DHPG (100 $\mu \mathrm{m}, 10 \mathrm{~min})$ induces LTD of fEPSPs in the presence of the src-family tyrosine kinase inhibitor PP2 $(10 \mu \mathrm{m})$. Bath application of DHPG also induces LTD of fEPSPS in the presence of PP2 and either of the tyrosine phosphatase inhibitors, orthovanadate (0V; $1 \mathrm{~mm} ; \boldsymbol{B})$ or PAO (15 $\mu \mathrm{M} ; \boldsymbol{C})$. $D$, Bath application of DHPG also induces LTD of fEPSPs in the presence of lavendustin A (Lav A; $10 \mu \mathrm{M})$ and orthovanadate $(0 \mathrm{~V} ; 1 \mathrm{~mm})$. $\boldsymbol{E}$, Bath application of DHPG also induces LTD of fEPSPs in the presence of genistein (Gen; $30 \mu \mathrm{m})$ and orthovanadate (1 mm). $\boldsymbol{F}$, Interleaved controls for this set of experiments. Calibration: $0.5 \mathrm{mV}, 5 \mathrm{~ms}$. Data are represented as mean \pm SEM. 
A

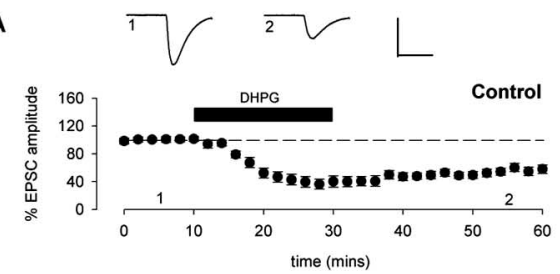

B

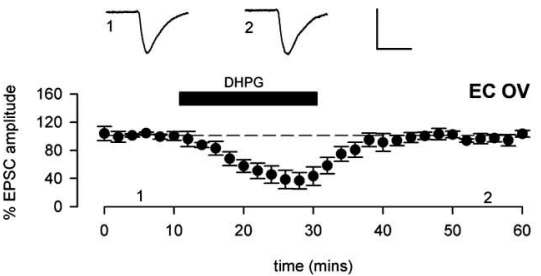

C

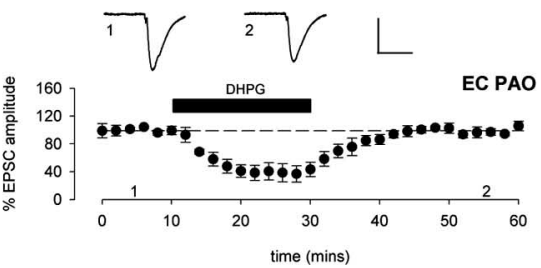

D

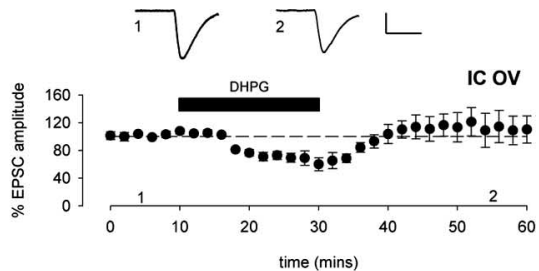

E

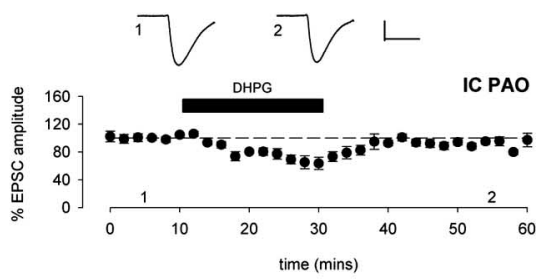

Figure 3. Postsynaptic PTPs are involved in DHPG-LTD. $\boldsymbol{A}$, Bath application of DHPG $(100 \mu \mathrm{m}, 20 \mathrm{~min})$ induces LTD of EPSCs. $\boldsymbol{B}$, In the presence of extracellularly applied orthovanadate (EC OV; $1 \mathrm{mM})$, DHPG-LTD is blocked. $C$, In the presence of extracellularly applied PAO (ECPA0; $15 \mu \mathrm{m})$, DHPG-LTD is also blocked. $D$, In the presence of orthovanadate delivered intracellularly via the patch pipette (IC OV; $100 \mu \mathrm{M}$ ) to the postsynaptic cell, DHPG-LTD is blocked. $E$, In the presence of PAO delivered intracellularly via the patch pipette (ICPA0; $1.5 \mu \mathrm{m}$ ) to the postsynaptic cell, DHPG-LTD is also blocked. Calibration: 100 pA, 50 ms. Data are represented as mean \pm SEM.

GluR2 $(1.96 \mathrm{mg} / \mathrm{ml})$, or rabbit anti-GluR2 $(0.25 \mathrm{mg} / \mathrm{ml})$ subunitselective antibodies in $5 \%(\mathrm{w} / \mathrm{v})$ milk powder in TBST, overnight at $4^{\circ} \mathrm{C}$. The immunolabeling obtained with the primary antibodies were revealed with the appropriate HRP-conjugated anti-guinea pig (1:7500 dilution; Jackson ImmunoResearch, West Grove, PA), HRP anti-mouse (1:7500 dilution; Sigma) or alkaline phosphatase-conjugated anti-rabbit (1:5000 dilution; Promega, Madison, WI) secondary antibodies for $2 \mathrm{~h}$ at room temperature. The enhanced chemiluminescence (ECL) detection system (Roche Diagnostics, Lewes, UK) was used for developing blots with HRP-conjugated antibodies. Lumi-Phos WB chemiluminescent substrate (Pierce, Rockford, IL) was used for alkaline phosphataseconjugated antibodies. The $\beta$-actin content of each input/homogenized slice sample was analyzed using an anti- $\beta$-actin mouse monoclonal antibody (Abcam, Cambridge, UK) visualized by an alkaline phosphataseconjugated secondary antibody (Promega) and Lumi-Phos WB chemiluminescent substrate (Pierce, Rockford). A series of antigen concentrations, primary and secondary antibody dilutions, and ECL exposure times were used to optimize our experimental conditions for the linear sensitivity range of the autoradiography film (Hyperfilm MP; Amersham Biosciences, Little Chalfont, Buckinghamshire, UK). Each immunoreactive band was subjected to densitometry using a Bio-Rad (Hercules, CA) imaging system (Quantity One) to determine the pixel volume (pixel intensity-by-area).

Immunofluorescence staining and imaging of hippocampal neurons. Hippocampal cultures were treated with agonists, with or without antagonists, as described in Figure 9. One hour later, cultures were fixed using 4\% paraformaldehyde in PBS for 15 min followed by incubation in $10 \mathrm{~mm}$ glycine in PBS for $5 \mathrm{~min}$ at $4^{\circ} \mathrm{C}$. Nonpermeabilized cells were washed in HBS $(119 \mathrm{~mm}$ $\mathrm{NaCl}, 5 \mathrm{~mm} \mathrm{KCl}, 25 \mathrm{~mm}$ HEPES, $33 \mathrm{~mm}$ D-glucose, $2 \mathrm{~mm} \mathrm{CaCl}_{2}, 2 \mathrm{~mm} \mathrm{MgCl}_{2}$, $1 \mu \mathrm{M}$ glycine, $\mathrm{pH} 7.4$; one time for $5 \mathrm{~min}$ ) and in $\mathrm{HBS}$ supplemented with $50 \%$ Neurobasal A and $0.5 \%$ horse serum (three times for $10 \mathrm{~min}$ ) at $4^{\circ} \mathrm{C}$. Surface GluR1 was labeled with an extracellular N-terminal domain-specific antibody $\left(1 \mu \mathrm{g} / \mathrm{ml}, 1 \mathrm{~h}, 4^{\circ} \mathrm{C}\right)$ (Molnar et al., 1993). After washing in $5 \%$ bovine serum albumin containing HBS (three times for $10 \mathrm{~min}$ ), cells were probed with Alexa 488-cojugated anti-rabbit secondary antibodies in HBS with $5 \%$ BSA for $1 \mathrm{~h}$ at $4^{\circ} \mathrm{C}$. Coverslips were mounted in Vectashield mounting medium (Vector Laboratories, Bretton, UK).

Images of immunolabeled neurons were captured using an inverted Zeiss (Oberkochen, Germany) LSM 510 Meta confocal laser scanning microscope using a $63 \times$ lens. The 488 and $633 \mathrm{~nm}$ laser bands of an Ar laser were used for dual dye excitation and FITC/tetramethylrhodamine isothiocyanate filters for fluorescence emission. The quantitative analysis was performed blind using NIH ImageJ (http://rsb.info.nih.gov/ij/index.html). The threshold for GluR1-positive fluorescent clusters (or puncta) was fixed at twice the level of background fluorescence obtained from a region of diffuse fluorescence within the dendritic shaft. Clusters were $\sim 1-2.5 \mu \mathrm{m}$ is size. Only puncta lying along processes interpreted as dendrites were counted. Regions where the clear identification of neuronal processes was ambiguous were excluded from the quantification. For statistical analysis, independent group $t$ tests were used. For quantitative comparisons, the number of puncta per $100 \mu \mathrm{m}$ length of dendrite was expressed for the GluR1 antibody within a given field.

\section{Results}

\section{PTP inhibitors block DHPG- but not} NMDA-induced LTD

In agreement with previous studies (Palmer et al., 1997; Fitzjohn et al., 1999; Huber et al., 2000; Rouach and Nicoll, 2003; Tan et al., 2003; Gallagher et al., 2004; Huang et al., 2004), bath application of (RS)-DHPG (100 $\mu \mathrm{M}, 10 \mathrm{~min}$ ) resulted in a sustained depression of synaptic transmission. Field EPSPs were depressed to $72 \pm 2 \%$ of baseline, 30 min after washout of DHPG ( $n=11 ; p<0.05$ vs baseline) (Fig. $1 A)$. The effects of DHPG were prevented by the specific mGluR5 antagonist 2-methyl-6-(phenylethynyl)pyridine hydrochloride (MPEP) (data not shown), which is consistent with DHPG-LTD being mediated via activation of mGluR5 (Palmer et al., 1997; Fitzjohn et al., 1999; Huang et al., 2004). Interleaved with control experiments, we applied one of two structurally distinct PTP inhibitors [orthovanadate, $1 \mathrm{~mm}$ and phenylarsine oxide (PAO), 15 $\mu \mathrm{M}]$. Neither compound affected baseline synaptic transmission (102 \pm 1 and $101 \pm 1 \%$ of baseline, respectively; data not shown), but both compounds attenuated DHPG-LTD ( $89 \pm 3 \%, n=6$, $p>0.05$; and $109 \pm 9 \%, n=6, p>0.05$, respectively) (Moult et al., 2002) (PAO data illustrated in Fig. $1 B$ ). In contrast, application of orthovanadate $(1 \mathrm{mM})$ or PAO $(15 \mu \mathrm{M})$ had no effect on pre-established DHPG-LTD; responses before and during orthovanadate application were $67 \pm 4$ and $74 \pm 4 \%$ of baseline $(n=3 ; p>0.05)$; responses before and during PAO application were $68 \pm 4$ and $73 \pm 3 \%$ of control $(n=3 ; p>0.05)$ (Fig. $1 C)$.

To determine whether PTP inhibition selectively blocked DHPG-LTD, the two PTP inhibitors were tested against NMDAR-LTD, in slices obtained from 3-week-old rats. NMDA (20 $\mu \mathrm{M}, 3 \mathrm{~min}$ ) caused a large initial depression of synaptic transmission followed by a sustained depression $(71 \pm 6 \%$; $p<0.05$; $n=8$ ) (Fig. $1 D$ ). In contrast to DHPG-LTD, neither orthovanadate nor PAO blocked NMDAR-LTD $(64 \pm 4 \%, n=5, p<0.05$; and $63 \pm 5 \%, n=5, p<0.05$, respectively) (PAO data illustrated in Fig. $1 E$ ). These results indicate that the block of DHPG-LTD by either orthovanadate or PAO is unlikely to be caused by some nonspecific effect. 


\section{Protein tyrosine kinase inhibitors prevent the effects of} PTP inhibitors

We reported previously that the protein tyrosine kinase (PTK) inhibitors genistein and lavendustin A had no significant effect on baseline transmission or DHPG-LTD (Moult et al., 2002). Similarly, we find that the src-family PTK inhibitor 3-(4chlorophenyl)1-(1,1-dimethylethyl)-1 H-pyrazolo[3,4-

d]pyrimidin-4-amine (PP2) had no effect on baseline synaptic transmission or on DHPG-LTD $(70 \pm 5 \% ; n=6 ; p<0.05)$ (Fig. $2 A)$. Surprisingly, however, PP2 completely prevented the inhibition of DHPG-LTD by orthovanadate $(76 \pm 7 \% ; n=6$; $p<$ $0.05)$ (Fig. $2 B$ ) or PAO (72 $\pm 7 \% ; n=6 ; p<0.05)$ (Fig. $2 C)$. This effect was not unique to PP2, because both genistein and lavendustin A prevented the inhibition of DHPG-LTD by orthovanadate $[73 \pm 9 \%, n=6, p<0.05$ (Fig. $2 D$ ); and $66 \pm 5 \%, n=6, p<$ 0.05 (Fig. $2 E$ ), respectively] or PAO $(74 \pm 5 \%, n=6, p<0.05$; and $67 \pm 7 \%, n=6, p<0.05$, respectively; data not illustrated). In all cases, these effects were not significantly different from interleaved controls ( $72 \pm 3 \% ; n=8)$ (Fig. $2 F)$. Thus, three structurally distinct PTK inhibitors have no direct effect on baseline transmission or DHPG-LTD but are able to completely prevent the effects of the PTP inhibitors.

\section{Analysis of DHPG-LTD using whole-cell recording}

To investigate the mechanism of DHPG-LTD, we made wholecell recordings from hippocampal slices (Fig. 3). In agreement with the extracellular experiments, DHPG $(100 \mu \mathrm{M}, 20 \mathrm{~min})$ was able to induce LTD $(59 \pm 8 \% ; n=13 ; p<0.05)$ (Fig. 3A) without affecting the holding current of the cesium-loaded neurons. In interleaved experiments, DHPG-LTD was blocked by bath application of orthovanadate ( $96 \pm 5 \% ; n=6 ; p>0.05$ ) (Fig. $3 B$ ) or PAO (97 $\pm 4 \% ; n=6 ; p>0.05$ ) (Fig. $3 C$ ) or by patch loading of $100 \mu \mathrm{M}$ orthovanadate $(111 \pm 14 \% ; n=6 ; p>0.05)$ (Fig. $3 D$ ) or $1.5 \mu \mathrm{M}$ PAO $(92 \pm 9 \% ; n=6 ; p>0.05)$ (Fig. $3 E)$. This result is unlikely to be explained by diffusion of the inhibitors out of the loaded cell to inhibit presynaptic PTPs, because a 10-fold lower concentration of the inhibitors was included in the patch solution compared with bath application. These data suggest that the PTPs critical for the induction of LTD are located in the postsynaptic neuron.

Several studies have reported that DHPG-LTD is associated with changes in $\mathrm{PPF}$, which is classically interpreted as an alteration in the probability of release $\left(P_{\mathrm{r}}\right)$. Such a finding is not readily compatible with the observation that postsynaptic loading of PTP inhibitors blocks DHPGLTD. One possible explanation is that there are both presynaptic and postsynaptic mechanisms of expression of DHPGLTD and that PTP inhibitors only affect the postsynaptic changes, which may dominate in slices taken from older animals (Nosyreva and Huber, 2005). We therefore analyzed PPF in the whole-cell recording experiments from slices prepared from 10- to 12-week-old animals (Fig. $4 A-C$ ). In each experiment, two pulses were delivered at an interval of 50 $\mathrm{ms}$ and the paired-pulse ratio calculated 30 min after washout of DHPG. Under control conditions, DHPG caused an increase in the PPR (from $1.5 \pm 0.1$ to $1.9 \pm$

A

B
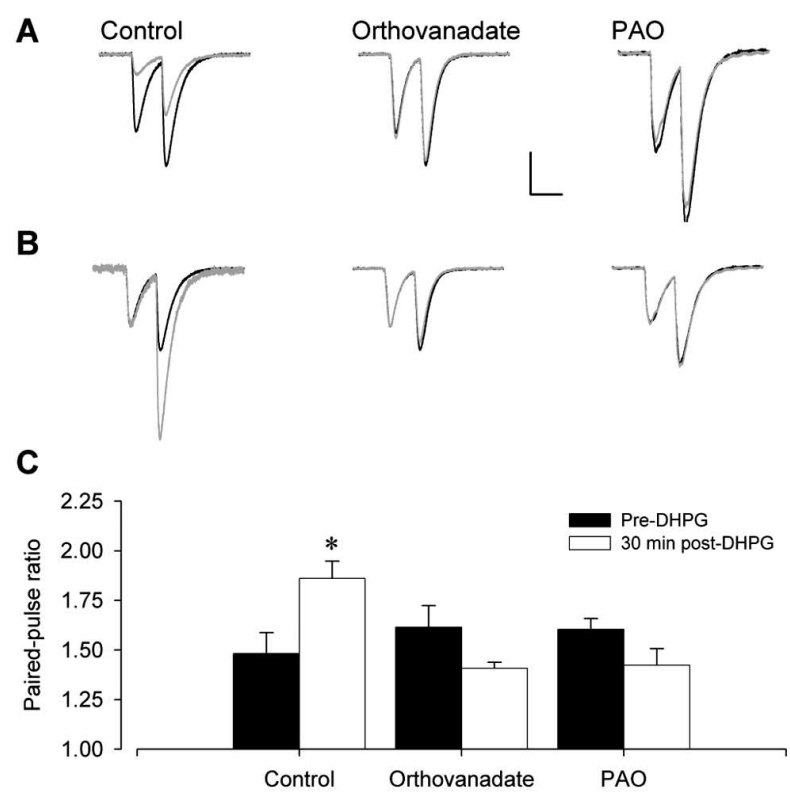

\section{D}

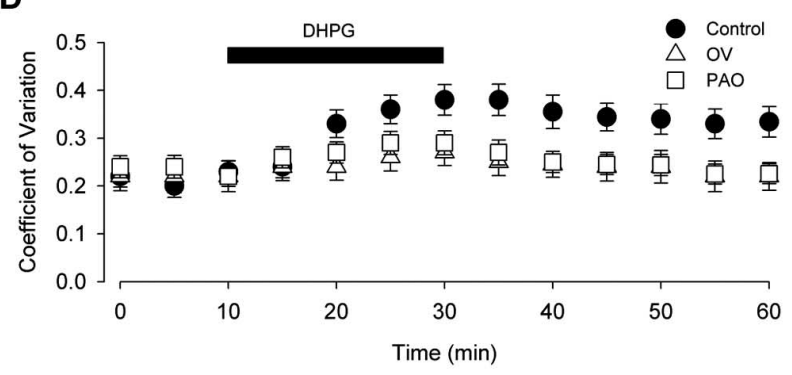

Figure 4. DHPG-LTD-associated increases in both PPR and CV are abolished by PTP inhibitors in the postsynaptic neuron. $A$, EPSC traces taken from representative experiments in which DHPG was applied under control recording conditions, or in which the filling solution contained either orthovanadate or PA0. Each trace shows the average of four successive EPSCs evoked by paired pulses before (black) and 30 min after (gray) DHPG application. Calibration: 100 pA, 50 ms. B, The same traces from $\boldsymbol{A}$ in which the first EPSCs are scaled, for better comparison. $\boldsymbol{C}$, Pooled data showing a significant increase in PPR under control conditions, which is abolished when postsynaptic PTPs are inhibited by either orthovanadate or $\mathrm{PAO} . \mathrm{D}, \mathrm{CV}$, measured during the same set of experiments, shows a significant and sustained increase after washout of DHPG. This sustained increase is abolished when either orthovanadate or PAO is included in the patch pipette. Data are represented as mean \pm SEM.
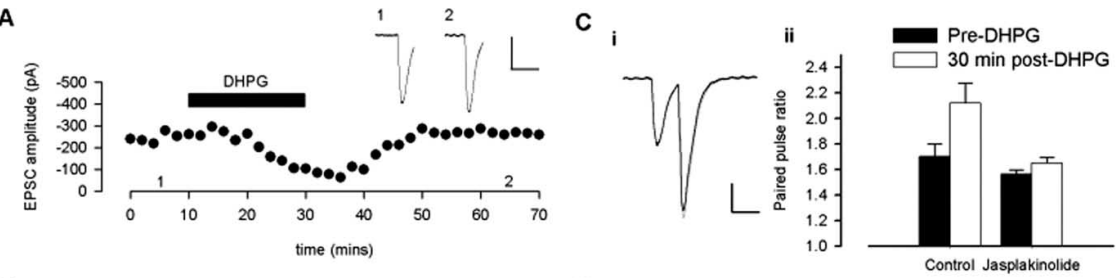

D
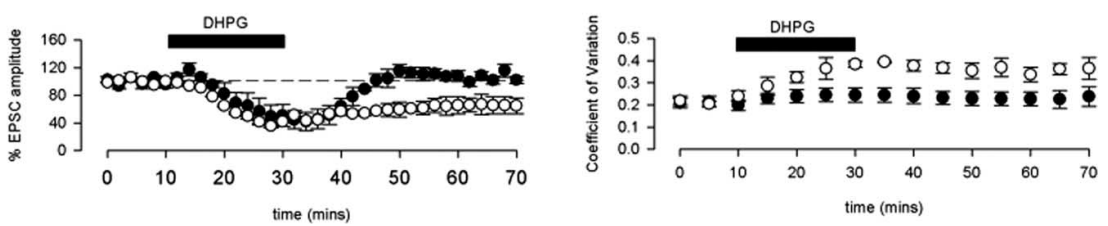

Figure 5. Jasplakinolide prevents DHPG-induced changes in PPF and CV.A, A representative experiment showing inhibition of DHPG-LTD by jasplakinolide $(2 \mu \mathrm{m})$, applied via the patch pipette. Individual EPSCs are taken from the time points indicated. Calibration: 100 pA, 50 ms. B, Pooled data, showing that DHPG-LTD is blocked after inclusion of jasplakinolide in the filling solution. $C$, There was no significant change in the PPR after DHPG. $C$, Individual traces taken from a representative experiment in which the first EPSC is scaled for better comparison. Cii, Pooled PPR data from four experiments. D, CV, measured during the same set of experiments, shows no significant change. In $\boldsymbol{B}-\boldsymbol{D}$ the two interleaved controls (mean and range) for this set of experiments are also plotted (white symbols in $\boldsymbol{B}, \boldsymbol{D}$ ). Data are represented as mean \pm SEM. 
A

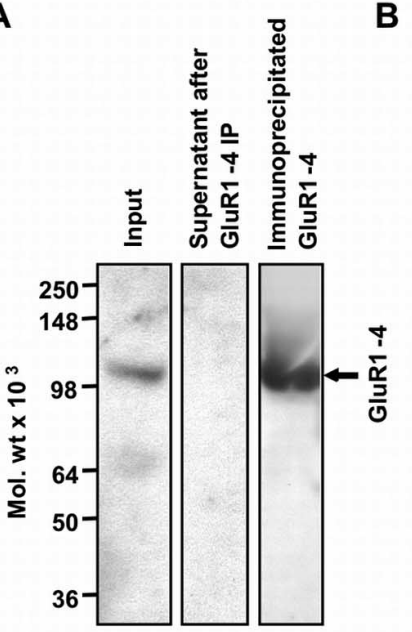

B

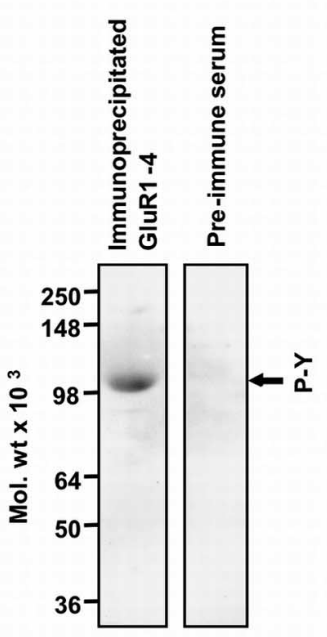

C

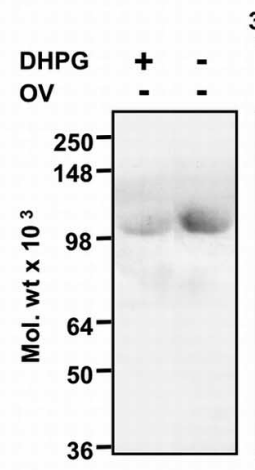

30 min wash
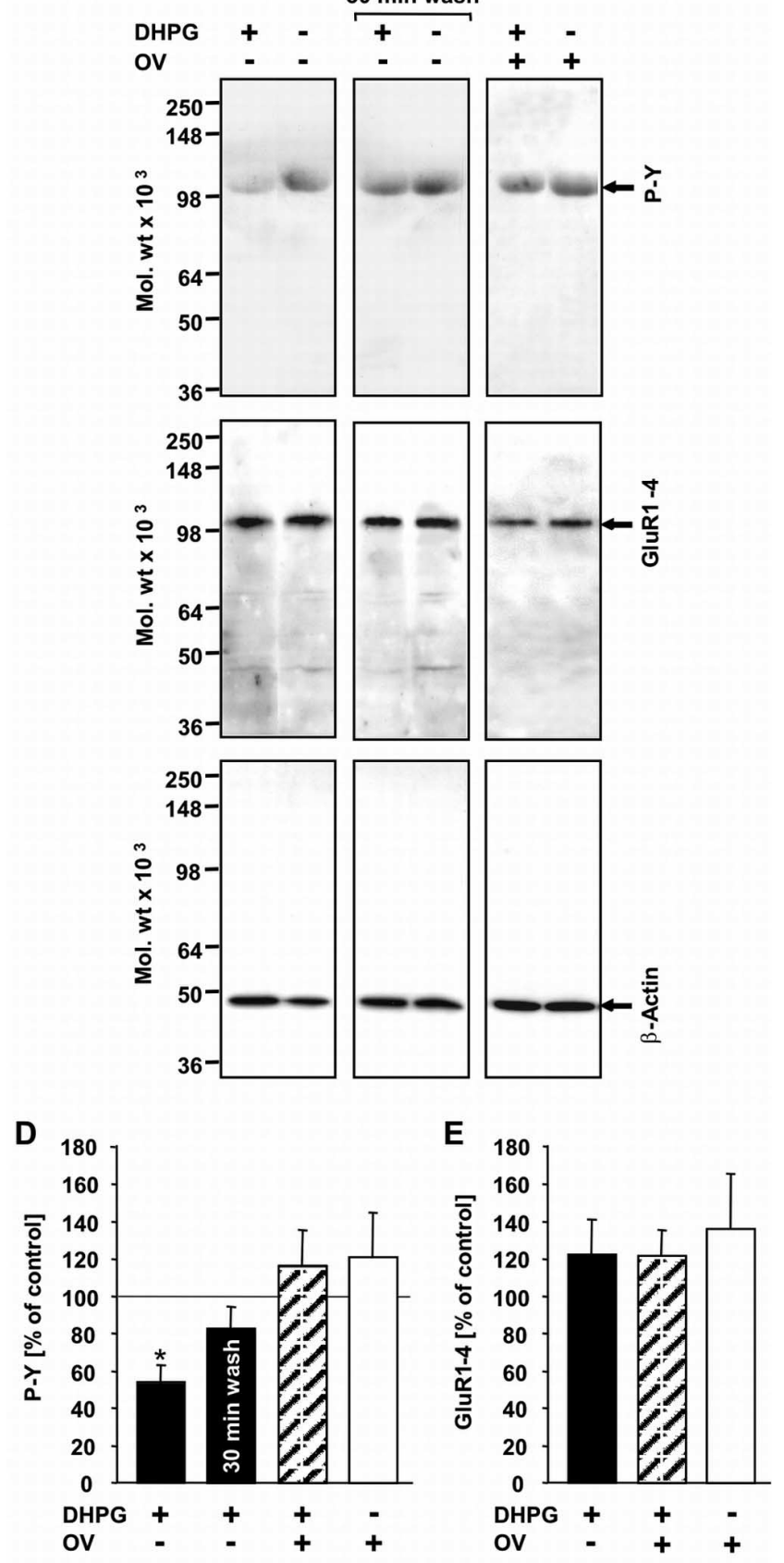

$0.1 ; n=13 ; p<0.05)$. In contrast, in neurons loaded with orthovanadate or PAO, there was no change in the PPR (in both cases, $1.6 \pm 0.1$ to $1.4 \pm 0.03 ; n=6 ; p>0.05)$. Similar results were obtained with the whole-cell recording experiments using bath-applied inhibitors (data not shown).

We also analyzed the CV for these experiments (Fig. 4D). Under control conditions, the CV of the first EPSC of the pair increased during application of DHPG, and this increase was sustained for as long as recordings were obtained. For example, 30 min after washout of DHPG, the CV had changed from $0.22 \pm$ 0.02 to $0.33 \pm 0.03(n=13 ; p<0.05)$. In contrast, in neurons loaded with orthovanadate or PAO, the $\mathrm{CV}$ was unchanged (orthovanadate, $0.22 \pm 0.03$ to $0.22 \pm 0.03, n=6, p>0.05$; PAO, $0.24 \pm 0.02$ to $0.23 \pm 0.02, n=6, p>0.05$ ). Again, similar results were obtained with the whole-cell recording experiments using bath-applied inhibitors (data not shown).

These results confirm that changes in PPF and CV are associated with DHPG-LTD. We now show that these changes, which are usually interpreted as being presynaptic in origin, are dependent on postsynaptic PTPs.

\section{Effects of jasplakinolide on DHPG-LTD}

There are, broadly speaking, two explanations for the observation that DHPG-LTD is associated with changes in PPF and CV. The first is that postsynaptic PTPs regulate neurotransmitter release, perhaps via release of a retrograde messenger. The second is that the alterations in PPF and CV reflect postsynaptic changes. To further investigate these possibilities, we applied the actin stabilizing drug jasplakinolide to the postsynaptic neuron. This compound has been shown to block AMPA receptor endocytosis induced by glutamate application (Zhou et al., 2001) and, furthermore, has been shown to block DHPG-induced LTD (Xiao et al., 2001). In agreement with this report, inclusion of jasplakinolide $(2 \mu \mathrm{M})$ in the recording solution completely blocked DHPG-LTD ( $2 \pm 2 \% ; n=4 ; p>0.05)$ (Fig. $5 A, B)$.

\footnotetext{
Figure 6. Regulation of tyrosine phosphorylation of AMPARs in hippocampal slices. $\boldsymbol{A}$, AMPARs were immunoprecipitated from Triton X-100-solubilized membrane fractions (input) of hippocampal slices $(400 \mu \mathrm{m})$ using a rabbit anti-GluR1- 4 polyclonal antibody. The immunoprecipitated AMPAR proteins were identified on immunoblots with an anti-GluR1- 4 guinea pig polyclonal antibody. Under our experimental conditions, all AMPAR subunits are immunoprecipitated from solubilized hippocampal slices. $\boldsymbol{B}$, The immunoprecipitated AMPARs were immunoblotted with an HRP-conjugated anti-P-Y antibody. The anti-P-Y antibody identified a band at $\sim 105 \mathrm{kDa}$, which corresponds to the predicted molecular weight of AMPA receptor subunit proteins. This band was not detectable in control samples in which the rabbit antiGluR1- 4 antibody was replaced by the same dilution of the preimmune serum during immunoprecipitation. C, AMPARs were immunoprecipitated from control, DHPG- (100 $\mu \mathrm{M})$, and/or orthovanadate- (OV; $1 \mathrm{~mm}$ ) treated hippocampal slices. Slices were taken at the end of a $10 \mathrm{~min}$ DHPG application and after 30 min washout (or equivalent time points for conditions in which DHPG was not applied). Representative immunoblots showing the transient reduction of tyrosine phosphorylation of AMPAR subunits induced by DHPG. The positions of the molecular weight markers are indicated on the left. $D, E$, Quantitative analysis of tyrosine phosphorylation of AMPARs $(\boldsymbol{D})$ and GluR1-4 protein content $(\boldsymbol{E})$ of hippocampal slices after DHPG and/or orthovanadate treatments. After optimization of experimental conditions to the linear sensitivity range of the autoradiography film, the relative P-Y and GluR1- 4 immunoreactivity was analyzed for each sample using densitometry in 6-11 independent experiments. $\boldsymbol{D}$, The P-Y immunoreactivity was normalized to the GluR1-4 content of each sample. E, The GluR1-4 immunoreactivity was normalized to the $\beta$-actin content of each sample. The normalized P-Y (D) and GluR1-4 (E) immunoreactivities are presented as percentage of the corresponding untreated control values. Quantification showed significantly reduced level of tyrosine phosphorylation of AMPARs 10 min after DHPG treatment $\left(\boldsymbol{D} ;{ }^{* *} p<0.02\right)$ without a significant change in the GluR1-4 content of hippocampal slices $(\boldsymbol{E})$. In the presence of orthovanadate, there was no significant reduction in P-Y immunoreactivity at 10 min after DHPG treatment. Data are represented as mean \pm SEM.
} 
Jasplakinolide also prevented the associated changes in PPF and CV (PPR, $1.6 \pm 0.04$ and $1.7 \pm 0.04, p>0.05$; CV, $0.22 \pm 0.02$ and $0.23 \pm 0.03, p>0.05$ ) (Fig. $5 C, D$ ). In two interleaved controls, DHPG-LTD was associated with changes in both PPF and $\mathrm{CV}$, similar to those shown in Figure 4.

\section{DHPG-LTD is associated with tyrosine dephosphorylation of} AMPAR subunits

Because postsynaptic PTPs are involved in DHPG-LTD, a possible target for tyrosine dephosphorylation is the AMPAR itself. Therefore, we next analyzed tyrosine phosphorylation levels of AMPAR subunit proteins. We developed conditions for the complete immunoprecipitation of all AMPARs from solubilized hippocampal slices, which are suitable for quantitative comparisons (Fig. 6A). Using an HRP-conjugated anti-P-Y antibody, a single $\sim 105 \mathrm{kDa}$ protein was identified in the immunoprecipitated fraction, which corresponds with the correct size for the AMPAR subunit proteins (Fig. 6B). The clearly detectable P-Y immunoreactivity in the immunoprecipitated fractions obtained from nontreated hippocampal slices indicates that at least some of the AMPARs are phosphorylated at tyrosine residues under basal conditions. After DHPG treatment of hippocampal slices (100 $\mu \mathrm{M}, 10 \mathrm{~min})$, the level of P-Y AMPAR immunoreactivity was substantially decreased $(56 \pm 12 \% ; n=11 ; p<0.05$ ) (Fig. $6 C, D)$. The DHPG-induced reduction in tyrosine phosphorylation of AMPARs was transient and returned to control levels $30 \mathrm{~min}$ after DHPG treatment ( $82 \pm 13 \% ; n=5 ; p>0.05$ ) (Fig. $6 C, D$ ). The ability of DHPG to induce tyrosine dephosphorylation of AMPARs was blocked when DHPG was applied in the presence of orthovanadate $(118 \pm 24 \% ; n=6 ; p>0.05)$ (Fig. $6 C, D)$. The DHPG and/or orthovanadate treatments did not significantly change the total amount of AMPAR subunits (Fig. 6C,E). These results indicate that DHPG-LTD involves a transient tyrosine dephosphorylation of AMPARs.

To identify which AMPAR subunits are affected during DHPG-LTD, we separated individual AMPAR proteins in a RIPA buffer at $100^{\circ} \mathrm{C}$ before immunoprecipitation with GluR1- and GluR2-selective antibodies (Fig. 7). Immunoblot analysis of separately immunoprecipitated GluR1 and GluR2 proteins revealed that the phosphorylated tyrosine residues are mainly associated with the GluR2 subunit. Furthermore, there was a marked reduction in tyrosine phosphorylation of GluR2 after DHPG treatment without detectable changes in the phosphorylation state of GluR1. Indeed, in agreement with a previous study (Ahmadian et al., 2004), GluR1 showed virtually undetectable levels of tyrosine phosphorylation. These results demonstrate that DHPG treatment of hippocampal slices is associated with reduction in tyrosine phosphorylation of GluR2 subunits.

\section{DHPG-induced reduction in mEPSC frequency is blocked by PTP inhibition}

DHPG-LTD can also be observed in cultured dissociated hippocampal neurons, where it is manifest as a decrease in the frequency of mEPSCs (Fitzjohn et al., 2001; Snyder et al., 2001; Xiao et al., 2001). To determine whether this effect was also dependent on postsynaptic PTPs, we interleaved control experiments with experiments in which the whole-cell solution contained orthovanadate $(100 \mu \mathrm{M})$. In agreement with our previous findings (Fitzjohn et al., 2001), DHPG resulted in a persistent decrease in the frequency of mEPSCs (frequency, $80 \pm 5 \%$ of baseline $30 \mathrm{~min}$ after DHPG washout; $p<0.05 ; n=7$ ) (Fig. 8) but no change in the amplitude of mEPSCs (before DHPG, $17 \pm 1 \mathrm{pA} ; 30$ min after DHPG, $17 \pm 1 \mathrm{pA} ; p>0.05 ; n=7$ ) (Fig. 8). The effect of DHPG

\section{GluR1 IP GluR2 IP

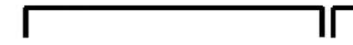

DHPG
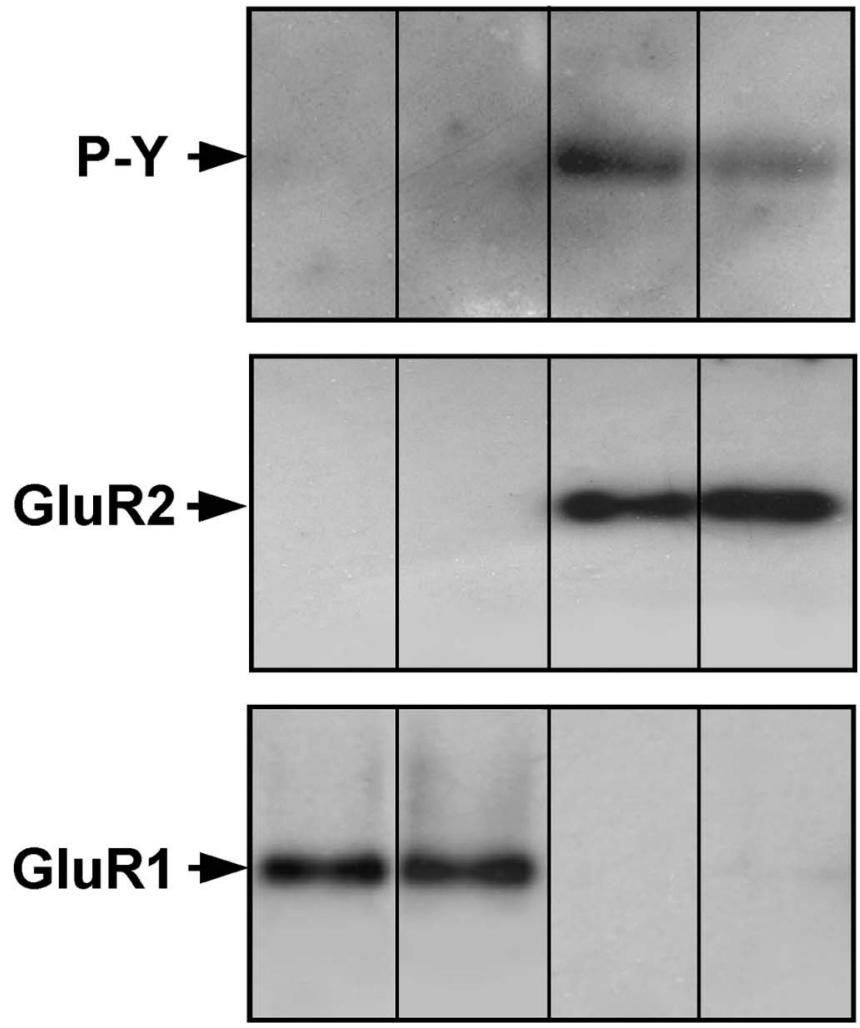

Figure 7. DHPG-LTD is associated with changes in tyrosine phosphorylation of the GluR2 subunit. Membrane fractions were obtained from control and DHPG-treated ( $100 \mathrm{~mm}, 10 \mathrm{~min}$ ) hippocampal slices. AMPAR subunits were solubilized and separated in RIPA buffer at $100^{\circ} \mathrm{C}$, and the GluR1 and GluR2 proteins were individually immunoprecipitated using subunit-specific antibodies. The immunoprecipitated GluR1 and GluR2 proteins were immunoblotted with the HRP-conjugated anti-P-Y antibody to reveal which subunit is phosphorylated at tyrosine residues. Whereas the GluR1 shows only very weak P-Y immunoreactivity with or without DHPG treatment, the GluR2 subunit strongly reacted with the anti-P-Y antibody. DHPG treatment produced a marked reduction in the anti-P-Y labeling of the GluR2 subunit compared with untreated controls. Immunostaining with the GluR1 and GluR2 subunit-specific antibodies confirmed the complete separation and selective immunoprecipitation of these proteins. The same pattern was obtained in three independent experiments.

on mEPSC frequency was blocked by orthovanadate $(30 \mathrm{~min}$ after DHPG application, mEPSC frequency was $102 \pm 12 \%$ of baseline; average mEPSC amplitude was $17 \pm 2$ and $16 \pm 2 \mathrm{pA}$ before and $30 \mathrm{~min}$ after DHPG, respectively; $p>0.05 ; n=9$ ) (Fig. 8). Therefore, cultured dissociated hippocampal neurons can be used to study PTP-dependent DHPG-LTD.

\section{DHPG-induced reduction in GluR1 cell surface clusters is selectively blocked by PTP inhibition}

It has been reported previously that DHPG-LTD is associated with changes in synaptic AMPAR number (Snyder et al., 2001; Xiao et al., 2001; Huang et al., 2004). We analyzed the surface density of AMPAR GluR1 subunits in cultured hippocampal neurons by an extracellular N-terminal domain-specific antibody (Molnar et al., 1993) and confocal imaging (Figs. 9, 10). Treatment with DHPG resulted in a reduction in GluR1immunopositive clusters (control, $24 \pm 2$ per $100 \mu \mathrm{m}$ dendrite, 

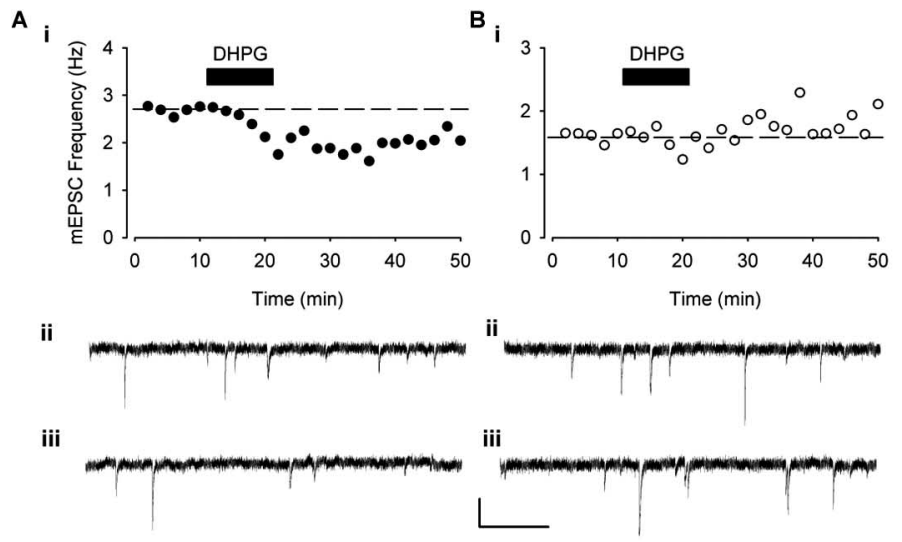

C

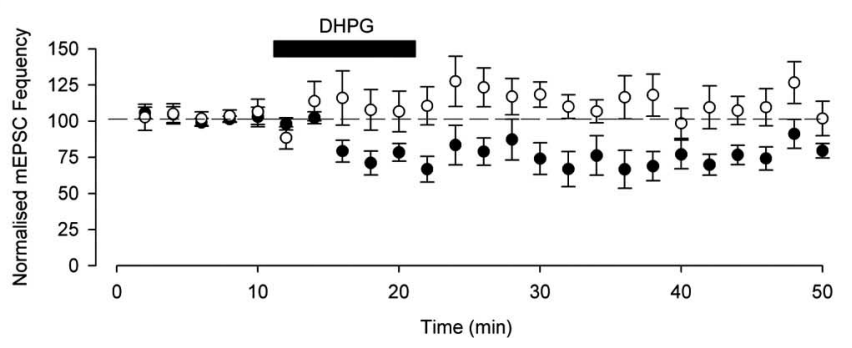

D

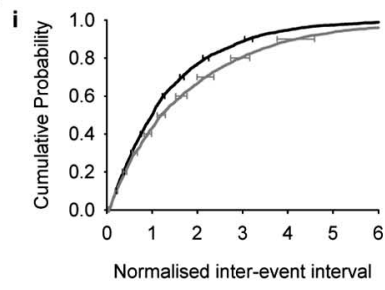

E

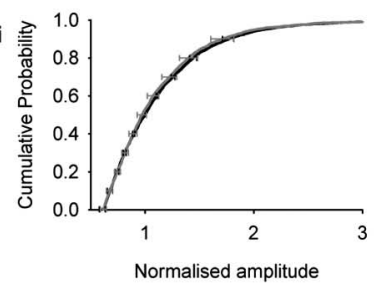

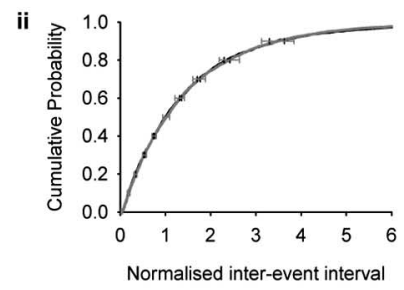

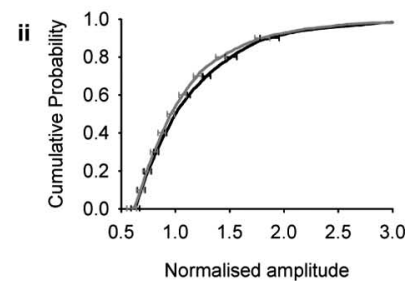

Figure 8. Intracellular orthovanadate blocks DHPG-induced changes in mEPSC frequency in cultured hippocampal neurons. $\boldsymbol{A}$, Under control conditions, DHPG (100 $\mu$ M) elicited a persistent decrease in mEPSC frequency recorded from dissociated hippocampal cultures (plotted as 2 min time bins; $\boldsymbol{A i}$ ). Aii, Aiii, Examples of mEPSCs recorded immediately before and 30 min after DHPG application, respectively. $\boldsymbol{B}$, When orthovanadate (100 $\mu \mathrm{m})$ was included in the whole-cell solution, DHPG failed to affect mEPSC frequency. Calibration: $20 \mathrm{pA}, 500 \mathrm{~ms}$. $\boldsymbol{C}$, Pooled data showing the effect of DHPG on mEPSC frequency under control conditions (filled circles; $n=7$ ) and in the presence of orthovanadate (open circles; $n=9$ ). $\boldsymbol{D}$, Pooled cumulative probability plots showing a change in interevent interval elicited by DHPG under control conditions (Di) but not in the presence of intracellular orthovanadate (Dii). Black line, mEPSCs recorded before DHPG application; gray line, $\mathrm{mEPSC}$ recorded 30 min after DHPG application. $\boldsymbol{E}$, mEPSC amplitude was unaffected by DHPG either under control conditions (Ei) or in the presence of orthovanadate (Eii). Data are represented as mean \pm SEM.

$n=9 ; \mathrm{DHPG}, 16 \pm 2$ per $100 \mu \mathrm{m}$ dendrite, $n=9 ; p<0.05)$. This effect of DHPG was dependent on activation of mGluR 5 but not mGluR1 or NMDA receptors, because it was blocked by $10 \mu \mathrm{M}$ MPEP ( $24 \pm 1$ per $100 \mu \mathrm{m}$ dendrite; $n=9 ; p>0.05$ ) but not by $100 \mu \mathrm{M}$ LY367385 ( $16 \pm 3$ per $100 \mu \mathrm{m}$ dendrite; $n=8 ; p<0.05$ ) or $5 \mu \mathrm{M} \mathrm{L}-689,560$ ( $14 \pm 2$ per $100 \mu \mathrm{m}$ dendrite; $n=8 ; p<0.05$ ), respectively (Fig. 10). Crucially, the effect of DHPG was blocked by orthovanadate ( $25 \pm 2$ per $100 \mu \mathrm{m}$ dendrite; $n=8 ; p>0.05)$. NMDA treatment also reduced GluR1-immunopositive clusters compared with controls ( $12 \pm 2$ per $100 \mu \mathrm{m}$ dendrite; $n=8$; $p<$ $0.05)$. However, the effect of NMDA was not blocked by orthovanadate $(10 \pm 2$ per $100 \mu \mathrm{m}$ dendrite; $n=4 ; p>0.05)$.

These results indicate that the DHPG-induced reduction in density of GluR1 surface clusters is an mGluR5- and PTPdependent process. The differential sensitivity to the PTP inhibitor orthovanadate suggests that DHPG- and NMDA-induced reduction in surface GluR1 puncta involves separate intracellular mechanisms.

\section{Discussion}

Recently, we reported that bath application of two structurally distinct PTP inhibitors (Coussens et al., 2000) can block the induction of DHPG-LTD (Moult et al., 2002). Our present observation that direct loading of a single neuron with either of these inhibitors is as effective as bath application strongly suggests that the critical PTP(s) associated with DHPG-LTD is located postsynaptically. The present study uses female rats, because our original description of DHPG-LTD (Palmer et al., 1997) and its subsequent characterization (Palmer et al., 1997; Schnabel et al., 2001; Moult et al., 2002; Rammes et al., 2003) were conducted using this sex. Although studies on male animals have reached broadly similar conclusions (Watabe et al., 2002; Rammes et al., 2003; Huang et al., 2004), it should be born in mind that possible sex linked differences could exist.

In addition to the sustained depression, DHPG induces a transient depression that is less sensitive or insensitive to PTP inhibitors. Surprisingly, although this transient depression was unaffected when the PTP inhibitors were bath applied, it was reduced when the PTP inhibitors were loaded directly into the postsynaptic cell. This might reflect a lower effective concentration of the bath-applied inhibitors at their postsynaptic site of action. However, the finding that PTP inhibitors block DHPG-LTD while having either a small or no effect on the transient depression suggest that not all group I mGluR-mediated effects may involve activation of PTPs to the same extent. The involvement of PTPs in other group I mGluR effects has also been demonstrated recently. For example, PTP inhibition can reduce the block of the slow-duration afterhyperpolarization seen with DHPG treatment in CA1 pyramidal neurons (Ireland et al., 2004) and also reduce the mGluR1-dependent slow EPSC seen in cerebellar Purkinje neurons (Canepari and Ogden, 2003). Thus, group I mGluR signaling may couple to PTP activation, producing a variety of actions. What is currently unknown is whether mGluR activation couples directly to PTP activation or whether this requires a number of intermediary steps.

\section{Tyrosine dephosphorylation of AMPARs is involved in DHPG-LTD}

Our data show that DHPG treatment decreases the level of tyrosine-phosphorylated AMPAR protein, with no change in total AMPAR expression. This effect is blocked in the presence of orthovanadate. Thus, it is likely that tyrosine dephosphorylation 

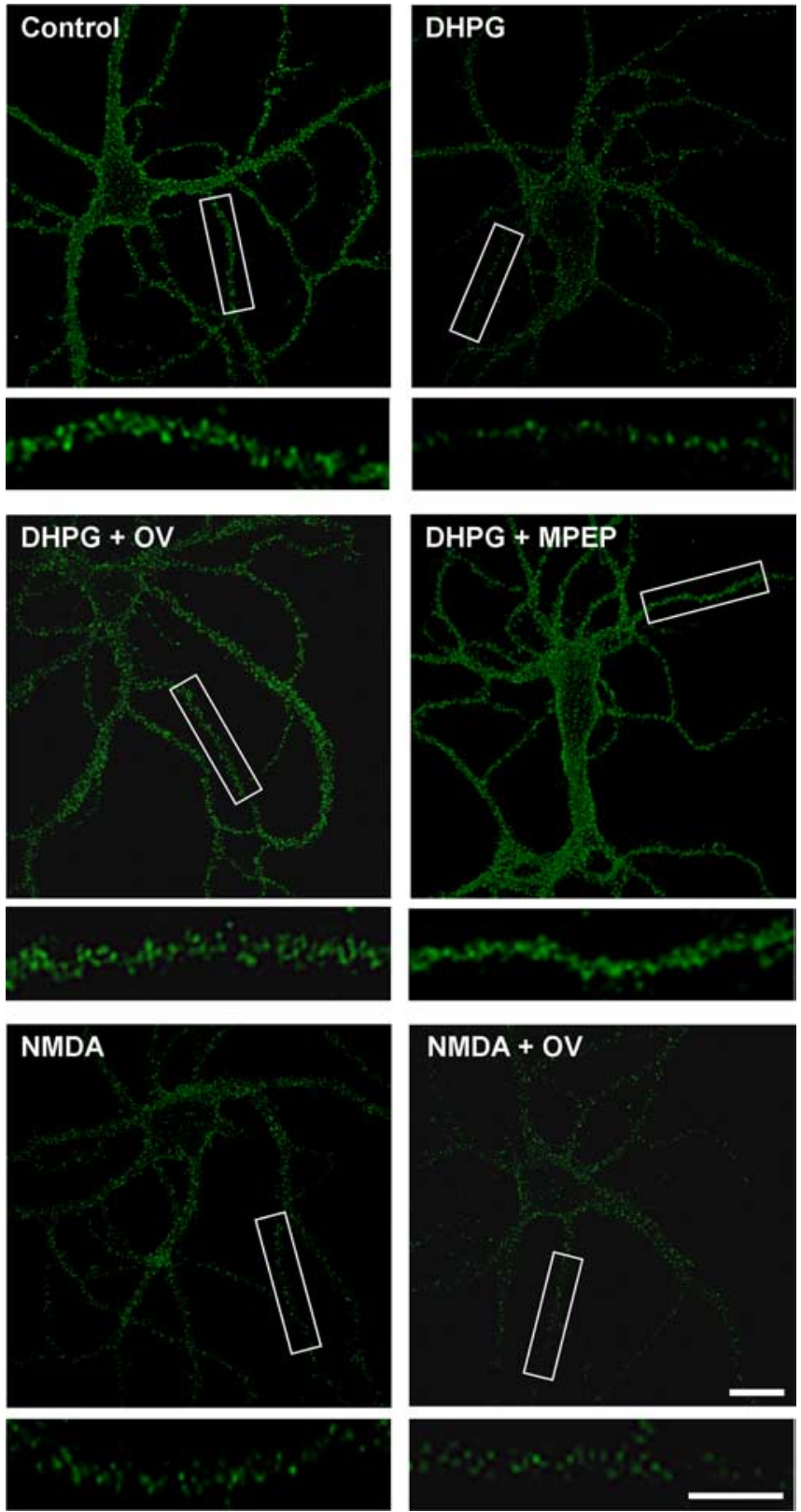

Figure 9. Immunocytochemical analysis of GluR1 AMPAR subunit distribution on the surface of cultured hippocampal neurons. Representative immunostained neurons ( $14 \mathrm{~d}$ in vitro) are presented for the following conditions: control, untreated hippocampal neurons; DHPG, neurons treated with DHPG $(100 \mu \mathrm{m}, 10 \mathrm{~min})$; DHPG $+0 \mathrm{~V}$, neurons treated with DHPG in the presence of orthovanadate (1 mM); DHPG + MPEP, DHPG treatment was performed in the presence of the mGluR5 antagonist MPEP $(10 \mu \mathrm{M})$; NMDA, neurons treated with NMDA $(20 \mu \mathrm{M}$, $3 \mathrm{~min}) ; \mathrm{NMDA}+\mathrm{OV}$, NMDA treatment was performed in the presence of orthovanadate (1 $\mathrm{mm}$ ). Scale bars: top panels, $20 \mu \mathrm{m}$; enlarged areas, $5 \mu \mathrm{m}$.

of AMPAR subunits is involved in the expression of DHPG-LTD, possibly via an effect on AMPAR trafficking. Because we see only a transient change in tyrosine phosphorylation of AMPARs, it is likely that this change provides a trigger for the internalization process. Our findings suggest that it is the GluR2 subunit that is regulated by changes in tyrosine phosphorylation during DHPGLTD. GluR1 surface expression decreases with DHPG treatment, yet the tyrosine phosphorylation state of GluR1 is not altered by DHPG. This suggests that the change in GluR2 phosphorylation is sufficient to drive changes in the surface expression of heteromeric AMPA receptor assemblies. Previous work has identified

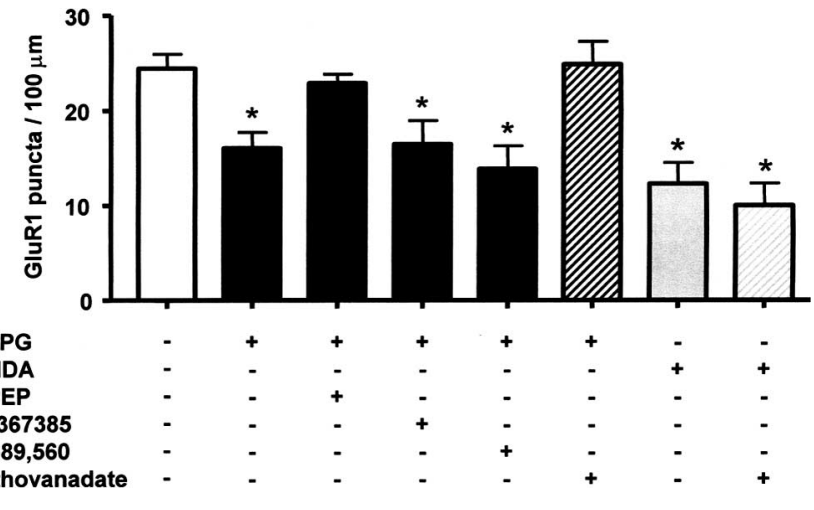

Figure 10. Quantitative analysis of changes in GluR1 AMPA receptor distribution on the surface of hippocampal neurons after DHPG and NMDA treatments. The diagram summarizes pooled data from at least four experiments. ${ }^{*} p<0.05$. Data are represented as mean \pm SEM.

the GluR2 subunit as being critically involved in AMPAR trafficking (Nishimune et al., 1998). Interestingly, during insulinstimulated LTD, there is phosphorylation of tyrosine residues of GluR2 that is associated with AMPAR internalization (Ahmadian et al., 2004). Therefore, both tyrosine phosphorylation and dephosphorylation could regulate different aspects of AMPAR trafficking at synapses.

A surprising observation was that, although PTK inhibitors had no significant effect on DHPG-LTD per se, they were able to completely block the effects of PTP inhibitors. A similar regulation of PTPs by PTKs has been reported with respect to the inhibition of NMDAR-mediated synaptic transmission (Coussens et al., 2000). One possible mechanism to explain our current observations involves two parallel induction pathways. One path is independent of tyrosine phosphorylation and may involve, for example, a MAPK cascade (Gallagher et al., 2004; Huang et al., 2004). The second pathway involves activation of a PTP to inhibit a PTK, resulting in a dephosphorylayion of AMPARs. Both pathways must be stimulated by mGluR activation for LTD to be induced. Inhibition of PTP enables activation of the PTK to maintain the phosphorylation state of AMPARs and thereby inhibit the induction of LTD. Inhibition of PTKs is not itself sufficient to induce LTD as the parallel pathway is not activated. However, PTK inhibitors counteract the effect of PTP inhibitors, because PTP inhibitors have their effect via activation of PTK.

An unusual aspect of DHPG-LTD is that it can be reversed during the application of an mGluR antagonist long after washout of DHPG (Palmer et al., 1997). This could be because DHPG induces a constitutively active state in mGluR5, and antagonists reverse this constitutive activity for as long as they are bound to the receptor. Therefore, the activation state of PTPs might mirror that of the mGluR5, such that PTPs become persistently activated. However, we found that neither PAO nor orthovanadate was able to reverse DHPG-LTD when applied 30 min after washout of DHPG. Furthermore, we found that the decrease in tyrosine phosphorylation had essentially recovered to control levels 30 min after treatment with DHPG. These data are more compatible with a transient dephosphorylation resulting in a persistent alteration in AMPARs at the synapse.

\section{Expression mechanism of DHPG-LTD}

In agreement with previous reports, in the current study, DHPGLTD was associated with an increase in the PPR and CV of EPSCs and a decrease in mEPSC frequency (Fitzjohn et al., 2001; Rouach and Nicoll, 2003; Tan et al., 2003). An increase in failure rate 
during DHPG-LTD in slices has also been reported (Fitzjohn et al., 2001). The simplest interpretation of these observations is that DHPG-LTD involves a decrease in $P_{\mathrm{r}}$. In addition, other evidence has suggested a presynaptic mechanism of expression of DHPG-LTD in 5- to 7-week-old mice (Watabe et al., 2002). We have now found that the changes in PPR, CV, and MEPSC frequency are prevented by postsynaptic block of PTPs. One possibility, therefore, is that during DHPG-LTD, postsynaptic PTP activation leads to a decrease in transmitter release, perhaps via regulation of a retrograde messenger. Indeed, there is evidence that synaptically induced mGluR-LTD is induced postsynaptically yet is expressed presynaptically (Bolshakov and Siegelbaum, 1994; Oliet et al., 1997; Zakharenko et al., 2002) and involves retrograde signaling involving 12-lipoxygenase metabolites of arachidonic acid (Feinmark et al., 2003).

Recently, Nosyreva and Huber (2005) suggested that the site of expression of mGluR-LTD is developmentally regulated, because there is a greater change in PPF in neonatal [postnatal day 8 (P8) to P15] compared with adolescent (P21-P35) animals. Conversely, changes in surface expression of AMPARs associated with DHPG-LTD were only observed in adolescent animals. However, our electrophysiological experiments, which revealed consistent effects on PPR, were conducted in slices obtained from young adult rats of 10-12 weeks of age, and previous work has reported changes in PPF in animals ranging from 2 to 6 weeks of age (Fitzjohn et al., 2001; Rouach and Nicoll, 2003; Tan et al., 2003). Therefore, although there may be quantitative differences, changes in PPF associated with DHPG-LTD are observed across all age ranges examined.

In the present study, we confirmed that there was a decrease of surface GluR1 AMPAR subunit clusters after DHPG treatment (Snyder et al., 2001; Xiao et al., 2001; Huang et al., 2004). We found that block of PTP prevented the DHPG-induced decrease in surface GluR1 AMPA receptor proteins. This effect of PTP inhibition was specific for DHPG-LTD, because the NMDAinduced decrease of GluR1 surface staining was unaffected by orthovanadate. A simple explanation for these results is that postsynaptic PTP activation leads to removal of AMPARs from the synapse. It is therefore possible that postsynaptic activation of PTP triggers a combination of presynaptic and postsynaptic expression mechanisms. An alternative explanation is that DHPGLTD expression is entirely postsynaptic but that it appears to be presynaptic as assessed by electrophysiological measures. This scenario could occur if DHPG brought about complete silencing of synapses by removal of the postsynaptic AMPAR complement (Snyder et al., 2001). This could account for the reported changes in failure rate and mEPSC frequency as well as the alteration in CV observed in this and a previous study (Fitzjohn et al., 2001). The reduction in AMPAR clusters is consistent with this possibility. In addition, the increase in PPF would occur if high $P_{\mathrm{r}}$ synapses were preferentially silenced, as suggested previously (Fitzjohn et al., 2001). The finding that jasplakinolide also blocked changes in PPF and CV associated with DHPG-LTD also supports the idea that alterations in AMPAR trafficking can account for the alterations in CV and PPF. Therefore, a purely postsynaptic mechanism for the induction and expression of DHPG-LTD is the simplest explanation for our observations. Previously, we found that, whereas NMDAR-LTD is associated with a reduction in sensitivity to uncaged L-glutamate, DHPG is not associated with any change (Rammes et al., 2003). We interpreted this result to mean that DHPG is either caused by a presynaptic mechanism or to lateral diffusion of AMPARs to extrasynaptic sites that are affected by the L-glutamate application. In light of the present findings, the latter possibility is the more likely explanation for these results. Therefore, it seems likely that DHPG-LTD involves PTP-regulated lateral diffusion of AMPARs away from the synaptic site.

\section{References}

Ahmadian G, Ju W, Liu L, Wyszynski M, Lee SH, Dunah AW, Taghibiglou C, Wang Y, Lu J, Wong TP, Sheng M, Wang YT (2004) Tyrosine phosphorylation of GluR2 is required for insulin-stimulated AMPA receptor endocytosis and LTD. EMBO J 23:1040-1050.

Anderson WW, Collingridge GL (2001) The LTP program: a data acquisition program for on-line analysis of long-term potentiation and other synaptic events. J Neurosci Methods 108:71-83.

Ashby MC, De La Rue SA, Ralph GS, Uney J, Collingridge GL, Henley JM (2004) Removal of AMPA receptors (AMPARs) from synapses is preceded by transient endocytosis of extrasynaptic AMPARs. J Neurosci 24:5172-5176.

Bashir ZI, Collingridge GL (1994) An investigation of depotentiation of long-term potentiation in the CAl region of the hippocampus. Exp Brain Res 100:437-443.

Bashir ZI, Jane DE, Sunter DC, Watkins JC, Collingridge GL (1993) Metabotropic glutamate receptors contribute to the induction of longterm depression in the CA1 region of the hippocampus. Eur J Pharmacol 239:265-266.

Bear MF, Abraham WC (1996) Long-term depression in hippocampus. Annu Rev Neurosci 19:437-462.

Beattie EC, Carroll RC, Yu X, Morishita W, Yasuda H, von Zastrow M, Malenka RC (2000) Regulation of AMPA receptor endocytosis by a signaling mechanism shared with LTD. Nat Neurosci 3:1291-1300.

Blake JF, Brown MW, Collingridge GL (1988) A quantitative study of the actions of excitatory amino acids and antagonists in rat hippocampal slices. Br J Pharmacol 95:291-299.

Bliss TV, Collingridge GL (1993) A synaptic model of memory: long-term potentiation in the hippocampus. Nature 361:31-39.

Bolshakov VY, Siegelbaum SA (1994) Postsynaptic induction and presynaptic expression of hippocampal long-term depression. Science 264:1148-1152.

Canepari M, Ogden D (2003) Evidence for protein tyrosine phosphatase, tyrosine kinase, and G-protein regulation of the parallel fiber metabotropic slow EPSC of rat cerebellar Purkinje neurons. J Neurosci 23:4066-4071.

Coussens CM, Williams JM, Ireland DR, Abraham WC (2000) Tyrosine phosphorylation-dependent inhibition of hippocampal synaptic plasticity. Neuropharmacology 39:2267-2277.

Dudek SM, Bear MF (1992) Homosynaptic long-term depression in area CA1 of hippocampus and effects of $N$-methyl-D-aspartate receptor blockade. Proc Natl Acad Sci USA 89:4363-4367.

Feinmark SJ, Begum R, Tsvetkov E, Goussakov I, Funk CD, Siegelbaum SA, Bolshakov VY (2003) 12-Lipoxygenase metabolites of arachidonic acid mediate metabotropic glutamate receptor-dependent long-term depression at hippocampal CA3-CA1 synapses. J Neurosci 23:11427-11435.

Fitzjohn SM, Kingston AE, Lodge D, Collingridge GL (1999) DHPGinduced LTD in area CA1 of juvenile rat hippocampus; characterisation and sensitivity to novel mGlu receptor antagonists. Neuropharmacology 38:1577-1583.

Fitzjohn SM, Palmer MJ, May JE, Neeson A, Morris SA, Collingridge GL (2001) A characterisation of long-term depression induced by metabotropic glutamate receptor activation in the rat hippocampus in vitro. J Physiol (Lond) 537:421-430.

Gallagher SM, Daly CA, Bear MF, Huber KM (2004) Extracellular signalregulated protein kinase activation is required for metabotropic glutamate receptor-dependent long-term depression in hippocampal area CA1. J Neurosci 24:4859-4864.

Huang CC, You JL, Wu MY, Hsu KS (2004) Rap1-induced p38 mitogenactivated protein kinase activation facilitates AMPA receptor trafficking via the GDI.Rab5 complex. Potential role in (S)-3,5dihydroxyphenylglycene-induced long term depression. J Biol Chem 279:12286-12292.

Huber KM, Kayser MS, Bear MF (2000) Role for rapid dendritic protein synthesis in hippocampal mGluR-dependent long-term depression. Science 288:1254-1257.

Huber KM, Roder JC, Bear MF (2001) Chemical induction of mGluR5- and 
protein synthesis-dependent long-term depression in hippocampal area CA1. J Neurophysiol 86:321-325.

Ireland DR, Guevremont D, Williams JM, Abraham WC (2004) Metabotropic glutamate receptor-mediated depression of the slow afterhyperpolarization is gated by tyrosine phosphatases in hippocampal CA1 pyramidal neurons. J Neurophysiol 92:2811-2819.

Kullmann DM (1994) Amplitude fluctuations of dual-component EPSCs in hippocampal pyramidal cells: implications for long-term potentiation. Neuron 12:1111-1120.

Lee HK, Kameyama K, Huganir RL, Bear MF (1998) NMDA induces longterm synaptic depression and dephosphorylation of the GluR1 subunit of AMPA receptors in hippocampus. Neuron 21:1151-1162.

Luthi A, Chittajallu R, Duprat F, Palmer MJ, Benke TA, Kidd FL, Henley JM, Isaac JT, Collingridge GL (1999) Hippocampal LTD expression involves a pool of AMPARs regulated by the NSF-GluR2 interaction. Neuron 24:389-399.

Molnar E, Baude A, Richmond SA, Patel PB, Somogyi P, McIlhinney RA (1993) Biochemical and immunocytochemical characterization of antipeptide antibodies to a cloned GluR1 glutamate receptor subunit: cellular and subcellular distribution in the rat forebrain. Neuroscience 53:307-326.

Moult PR, Schnabel R, Kilpatrick IC, Bashir ZI, Collingridge GL (2002) Tyrosine dephosphorylation underlies DHPG-induced LTD. Neuropharmacology 43:175-180.

Mulkey RM, Malenka RC (1992) Mechanisms underlying induction of homosynaptic long-term depression in area CA1 of the hippocampus. Neuron 9:967-975.

Nishimune A, Isaac JT, Molnar E, Noel J, Nash SR, Tagaya M, Collingridge GL, Nakanishi S, Henley JM (1998) NSF binding to GluR2 regulates synaptic transmission. Neuron 21:87-97.

Nosyreva ED, Huber KM (2005) Developmental switch in synaptic mechanisms of hippocampal metabotropic glutamate receptor-dependent longterm depression. J Neurosci 25:2992-3001.

Oliet SH, Malenka RC, Nicoll RA (1997) Two distinct forms of long-term depression coexist in CA1 hippocampal pyramidal cells. Neuron 18:969-982.

Palmer MJ, Irving AJ, Seabrook GR, Jane DE, Collingridge GL (1997) The group I mGlu receptor agonist DHPG induces a novel form of LTD in the CA1 region of the hippocampus. Neuropharmacology 36:1517-1532.

Pickard L, Noel J, Henley JM, Collingridge GL, Molnar E (2000) Developmental changes in synaptic AMPA and NMDA receptor distribution and AMPA receptor subunit composition in living hippocampal neurons. J Neurosci 20:7922-7931.

Pickard L, Noel J, Duckworth JK, Fitzjohn SM, Henley JM, Collingridge GL, Molnar E (2001) Transient synaptic activation of NMDA receptors leads to the insertion of native AMPA receptors at hippocampal neuronal plasma membranes. Neuropharmacology 41:700-713.

Rammes G, Palmer M, Eder M, Dodt HU, Zieglgansberger W, Collingridge GL (2003) Activation of mGlu receptors induces LTD without affecting postsynaptic sensitivity of CA1 neurons in rat hippocampal slices. J Physiol (Lond) 546:455-460.

Rouach N, Nicoll RA (2003) Endocannabinoids contribute to short-term but not long-term mGluR-induced depression in the hippocampus. Eur J Neurosci 18:1017-1020.

Schnabel R, Kilpatrick IC, Collingridge GL (2001) Protein phosphatase inhibitors facilitate DHPG-induced LTD in the CA1 region of the hippocampus. Br J Pharmacol 132:1095-1101.

Snyder EM, Philpot BD, Huber KM, Dong X, Fallon JR, Bear MF (2001) Internalization of ionotropic glutamate receptors in response to mGluR activation. Nat Neurosci 4:1079-1085.

Tan Y, Hori N, Carpenter DO (2003) The mechanism of presynaptic longterm depression mediated by group I metabotropic glutamate receptors. Cell Mol Neurobiol 23:187-203.

Watabe AM, Carlisle HJ, O’Dell TJ (2002) Postsynaptic induction and presynaptic expression of group $1 \mathrm{mGluR}$-dependent LTD in the hippocampal CA1 region. J Neurophysiol 87:1395-1403.

Xiao MY, Zhou Q, Nicoll RA (2001) Metabotropic glutamate receptor activation causes a rapid redistribution of AMPA receptors. Neuropharmacology 41:664-671.

Zakharenko SS, Zablow L, Siegelbaum SA (2002) Altered presynaptic vesicle release and cycling during mGluR-dependent LTD. Neuron 35:1099-1110.

Zhou Q, Xiao M, Nicoll RA (2001) Contribution of cytoskeleton to the internalization of AMPA receptors. Proc Natl Acad Sci USA 98:12611266. 